\title{
Nitric oxide-based protein modification: formation and site-specificity of protein S-nitrosylation
}

\author{
Izabella Kovacs and Christian Lindermayr* \\ Institute of Biochemical Plant Pathology, Helmholtz Zentrum München, German Research Center for Environmental Health, Munich, Germany
}

\section{Edited by:}

Jay Thelen, University of Missouri,

USA

\section{Reviewed by:}

Georgia Tanou, Aristotle University of Thessaloniki, Greece

Natalia V. Bykova, Memorial University of Newfoundland, Canada

\section{*Correspondence:}

Christian Lindermayr, Institute of Biochemical Plant Pathology, Helmholtz Zentrum München, German Research Center for Environmental Health, Ingolstädter Landstrasse 1, 85764 München-Neuherberg, Germany. e-mail: lindermayr@helmholtzmuenchen.de
Nitric oxide (NO) is a reactive free radical with pleiotropic functions that participates in diverse biological processes in plants, such as germination, root development, stomatal closing, abiotic stress, and defense responses. It acts mainly through redox-based modification of cysteine residue(s) of target proteins, called protein $S$-nitrosylation. In this way NO regulates numerous cellular functions and signaling events in plants. Identification of $S$-nitrosylated substrates and their exact target cysteine residue(s) is very important to reveal the molecular mechanisms and regulatory roles of $S$-nitrosylation. In addition to the necessity of protein-protein interaction for trans-nitrosylation and denitrosylation reactions, the cellular redox environment and cysteine thiol micro-environment have been proposed important factors for the specificity of protein $S$-nitrosylation. Several methods have recently been developed for the proteomic identification of target proteins. However, the specificity of NO-based cysteine modification is still less defined. In this review, we discuss formation and specificity of $S$-nitrosylation. Special focus will be on potential $S$-nitrosylation motifs, site-specific proteomic analyses, computational predictions using different algorithms, and on structural analysis of cysteine $S$-nitrosylation.

\section{Keywords: protein $S$-nitrosylation, nitric oxide, post-translational modification, cysteine residue, redox-} modification, site-specificity

\section{NITRIC OXIDE SIGNALING}

The free radical nitric oxide $(\mathrm{NO})$ as a unique gaseous second messenger controls fundamental biological functions in animals, plants, and microbes. NO was discovered as an endothelial-derived relaxing factor, that induced vascular relaxation in smooth muscle cells (Ignarro et al., 1987). Later, the identification of an amino acid L-arginine as a substrate to produce $\mathrm{NO}$ gas by a family of NO synthases in mammals and the generation of cyclic guanosine monophosphate (cGMP) after the activation of soluble guanylate cyclase (sGC) by NO (Palmer et al., 1988; Alderton et al., 2001; Cary et al., 2006), has led to the identification of a broad-spectrum of functions of $\mathrm{NO}$ in the cardiovascular, immune, nervous system, and human pathologies (Pacher et al., 2007). According to the recent knowledge on NO signaling in animals, the mode of action of NO is divided into three mechanisms. (I) The "classical" NO signaling, which is dependent upon sGC and its related enzymes. (II) The "less classical" NO signaling operates through the inhibition of cytochrome $c$ oxidase in mitochondria. Both signaling mechanisms (I and II) rely on direct binding of NO to protein metal centers through coordination chemistry. (III) The "non-classical" NO signaling is cGMP independent and related to the NO-mediated post-translational modifications of downstream proteins (Martinez-Ruiz et al., 2011).

With regard to higher plants, numerous studies have also shown the essential role of NO in growth and development (Astier et al., 2012), including seed germination (Bethke et al., 2006; Belenghi et al., 2007), primary and lateral root growth (Correa-Aragunde et al., 2004; Zhao et al., 2007), stomatal closure (Neill et al., 2002), flowering (He et al., 2004), pollen-tube growth regulation (Prado et al., 2004), and fruit ripening and senescence (Leshem et al., 1998; Corpas et al., 2004). Furthermore, NO is a crucial component of plant immune responses (Gaupels et al., 2011; Yu et al., 2012) and various abiotic stresses (Corpas et al., 2011). Despite the extensive studies on NO function in different processes of plants, the whole picture of NO impact on living cells, including production, activity, and metabolism of NO still has yet to be completed. Different mechanisms of NO signaling, according to the animal classification, have also been reported in plants. $\mathrm{Ca}^{2+}$ and cGMP are also involved in NO signaling as second messengers in response to biotic (Durner et al., 1998; Klessig et al., 2000; Ma et al., 2009) and abiotic stresses (Martinez-Atienza et al., 2007). However, the most studied mode of action of NO is protein S-nitrosylation, the covalent attachment of an NO group to the thiol site of protein cysteine. Protein $S$-nitrosylation, as a reversible post-translational modification affects protein activity (either by activation or inhibition), translocation and protein function. In this review, we discuss the mode of action of NO focusing on the formation and site-specific analysis of $S$-nitrosylation.

\section{$S$-NITROSYLATION AS A POST-TRANSLATIONAL MODIFICATION}

The ability of NO to diffuse across membranes, in addition to its radical nature, leads to the wide range of interactions with biological targets in a concentration and redox-dependent fashion. Investigations of different signaling events have revealed that temporal as well as spatial regulation of NO is required for efficient signal transduction. Protein $S$-nitrosylation has been established as a significant route by which $\mathrm{NO}$ transmits its ubiquitous cellular 
influence (Hess et al., 2005). Furthermore, other major types of modifications of NO have also been reported (Martinez-Ruiz et al., 2011; Astier and Lindermayr, 2012; Toledo and Augusto, 2012), such as metal nitrosylation or tyrosine nitration. The latter one is an irreversible reaction of a nitrating agent with a tyrosine residue of a target protein (Ford, 2010).

Furthermore, to make the signaling function of $S$-nitrosylation even more complex, a recent review in the animal field has summarized a growing number of examples, where the major protein post-translational modifications (e.g., phosphorylation, ubiquitylation, acetylation, sumoylation, palmitoylation) have also been affected and regulated by $S$-nitrosylation via signal crosstalks (Hess and Stamler, 2012). Besides S-nitrosylation, increasing interest and evidence point at the important role of protein denitrosylation as a feedback mechanism controlling NO signaling. The removal of NO group from proteins might occur through different enzyme systems, of which especially $S$-nitrosoglutathione (GSNO) reductase and thioredoxin play a predominant role (Benhar et al., 2009). Additionally, non-enzymatic denitrosylation has been described, for example, in response to exposure to heat, light, reducing agents, nucleophilic compounds, or by transition metals. As a result of complex functions of $S$-nitrosylation with different levels of regulation, the literature encompasses around 3000 $S$-nitroso proteins (including those identified by exogenous treatment, physiological, or by nitrosylating agents) from animals and plants, which highlight the importance of protein $S$-nitrosylation in a broad-spectrum of cellular processes (Hess and Stamler, 2012).

In recent years, much effort has been made to identify $S$-nitrosylated proteins in plants. A number of candidates have been identified from proteome-wide analyses using NO donors as $S$-nitrosylating agents (Table 1). These studies were based on the biotin switch technique (BST), which was the first assay designed to detect $S$-nitrosylated (SNO) proteins from cells and tissues. BST is a three-step method to convert SNO cysteines into biotinylated cysteine residues that easily be detected using streptavidin or a specific antibody (Jaffrey and Snyder, 2001). In the first step, the reduced protein thiols are blocked under denaturing conditions with $S$-thiomethylating agents, such as monomethyl thiosulfonate (MMTS), $N$-ethylmaleimide, or iodo-acetic acid. Following the blocking step, the SNO-bond is specifically reduced to a free thiol with ascorbate. Finally, free thiols are reacted with a thiol-specific reversible biotinylating agent, such as biotin-HPDP. Biotinylated proteins are visualized directly using an avidin antibody. Alternatively, biotinylated proteins are precipitated with immobilized avidin or streptavidin and analyzed by Western blotting for protein-of-interest or by mass spectrometry (MS). After the introduction of BST, increasing numbers of modifications have been reported due to some critical steps in the assay, which may result in false-positive detection of SNO sites. For example, in the first step it is crucial to minimize background biotinylation due to incomplete blocking and to maximize assay sensitivity (Forrester et al., 2009a). However, the most controversial issue is the efficiency and specificity of ascorbate in the second reduction step. Zhang et al. (2005) have reported that ascorbate is a very inefficient reducer of protein-SNOs and high ascorbate concentrations and long incubation times are necessary to achieve a quantitative reaction. Other studies on ascorbate specificity have shown that ascorbate accelerates the rate of the biotinylation reaction and increases the presence of false-positive signals (Huang and Chen, 2006) or can even reduce protein disulfides as in the case of microtubule proteins (Landino et al., 2006). These controversial results could be partially explained by the study of Forrester et al. (2007), who reported that the exposure of samples to indirect sunlight from a laboratory window could reduce the activated disulfide in biotin-HPDP and facilitate biotinylation of MMTS-blocked

Table 1 | Summary of proteomics approaches to identify candidate proteins for $\boldsymbol{S}$-nitrosylation in plants.

\begin{tabular}{|c|c|c|c|c|}
\hline Plant species & Tissue/organelle & Treatment & $\begin{array}{l}\text { No. of } \\
\text { identified } \\
\text { candidates }\end{array}$ & Reference \\
\hline Arabidopsis thaliana & Cell cultures & GSNO-treated protein extracts & 63 & Lindermayr et al. (2005) \\
\hline Arabidopsis thaliana & Leaves & Plants treated with gaseous NO & 52 & Lindermayr et al. (2005) \\
\hline Kalanchoe pinnata & Leaves & GSNO-treated protein extracts & 19 & Abat et al. (2008) \\
\hline Arabidopsis thaliana & Leaf mitochondria & GSNO-treated protein extracts & 11 & Palmieri et al. (2010) \\
\hline Arabidopsis thaliana & Cell cultures & GSNO-treated protein extracts & 27 & Maldonado-Alconada et al. (2011) \\
\hline Arabidopsis thaliana & Leaves & Pseudomonas syringae avir/vir & 119 & Maldonado-Alconada et al. (2011) \\
\hline Arabidopsis thaliana & Cell cultures & untreated & 53 & Fares etal. (2011) \\
\hline Solanum tuberosum & Leaves & GSNO-treated protein extracts & 34 & Kato et al. (2012) \\
\hline Solanum tuberosum & Tubers & GSNO-treated protein extracts & 46 & Kato et al. (2012) \\
\hline Oryza sativa (WT) & Leaves & High light & 73 & Lin et al. (2012) \\
\hline $\begin{array}{l}\text { Oryza sativa (nitric oxide } \\
\text { excess } 1 \text { mutant; noe1) }\end{array}$ & Leaves & High light & 100 & Lin et al. (2012) \\
\hline Pisum sativum & Leaf peroxisomes & GSNO-treated peroxisomes & 6 & Ortega-Galisteo et al. (2012) \\
\hline Pisum sativum & Leaf mitochondria & Salt-stressed plants & 24 & Camejo etal. (2012) \\
\hline
\end{tabular}


protein thiol. Ascorbate can also catalyze the $\mathrm{Cu}$-dependent reduction of SNOs to increase the specificity of BST (Wang et al., 2008), whereas it acts as a nucleophile in the absence of added metal ions (Holmes and Williams, 2000). Despite the controversial reports, the BST is the most widely used method of detection of SNO proteins in biological samples. The identified proteins from plant proteome-wide studies have been shown to take part in major cellular activities, notably primary and secondary metabolism, photosynthesis, protein folding and genetic information processing, cellular architecture, and response to biotic and abiotic stresses (Astier et al., 2012). Although the growing number of S-nitroso proteins that have been revealed, the characterization of these candidates needs confirmation by candidate-specific approaches in respect of their physiological relevance. To date, around 20 different $S$-nitrosylated proteins have been characterized in details in plants and most of them have been reviewed recently with regard to their functional significance in NO signaling (Astier et al., 2012; Yu et al., 2012).

\section{FORMATION OF $\boldsymbol{S}$-NITROSOTHIOLS}

The mechanism of formation of $S$-nitrosothiols in vivo is an important factor in understanding the biological actions of NO. The intrinsic biochemistry of NO suggests multiple reaction pathways for $S$-nitrosylation mechanisms based on various in vitro studies. Most of these studies have used thiol-containing molecules like cysteine and glutathione for $S$-nitrosylation to yield low molecular weight $S$-nitrosothiols such as $S$-nitrosocysteine and GSNO (Gow et al., 1997; Keszler et al., 2010). They form an integral part of the total cellular nitrosothiol (RSNO) pool and have potential roles as intermediates in transport, storage, and delivery of NO.

$\mathrm{NO}$ as a free radical ( $\mathrm{NO})$ can lose or gain electrons to become an oxidized nitrosonium cation $\left(\mathrm{NO}^{+}\right)$or a reduced nitroxyl anion $\left(\mathrm{NO}^{-}\right)$, each with a different oxidation state of the nitrogen atom $(+2,+3$, and +1 , respectively; Arnelle and Stamler, 1995). Furthermore, NO can be oxidized in an aerobic, biological milieu up to its +5 oxidation state yielding non-reactive nitrate anions $\left(\mathrm{NO}_{3}^{-}\right)$. The generation and the presence of different redox status of NO multiply the possibilities to produce $S$-nitrosylated proteins in numerous conditions.

NO is a poor oxidant and also a poor reducing agent under physiological conditions, therefore NO-dependent amino acid oxidation mostly occurs via secondary reactions after the oxidation of $\mathrm{NO}$ to nitrogen dioxide $\left(\mathrm{NO}_{2}\right)$, dinitrogen trioxide $\left(\mathrm{N}_{2} \mathrm{O}_{3}\right)$, or peroxynitrite $\left(\mathrm{ONOO}^{-}\right)$in the presence of oxygen or reactive oxygen species (Broniowska and Hogg, 2012). There are four major mechanisms of $S$-nitrosylation that have the potential to occur in biological systems: (1) an oxidative pathway with $\mathrm{NO}$ in a higher oxidation status, (2) a radical-mediated pathway with $\mathrm{NO}$ and thiyl (RS') radicals, (3) metal-catalyzed RSNO formation in the presence of transition metals, and (4) trans-nitrosylation. The different reactions are summarized in Figure 1.

\section{THE OXIDATIVE PATHWAY OF $\boldsymbol{S}$-NITROSYLATION}

In this pathway, $S$-nitrosylation is modulated by higher oxides of $\mathrm{NO}$, such as $\mathrm{NO}^{+}$and $\mathrm{N}_{2} \mathrm{O}_{3}$. RSNO can be formed by the direct addition of $\mathrm{NO}^{+}$to a thiol at neutral $\mathrm{pH}$, but the major

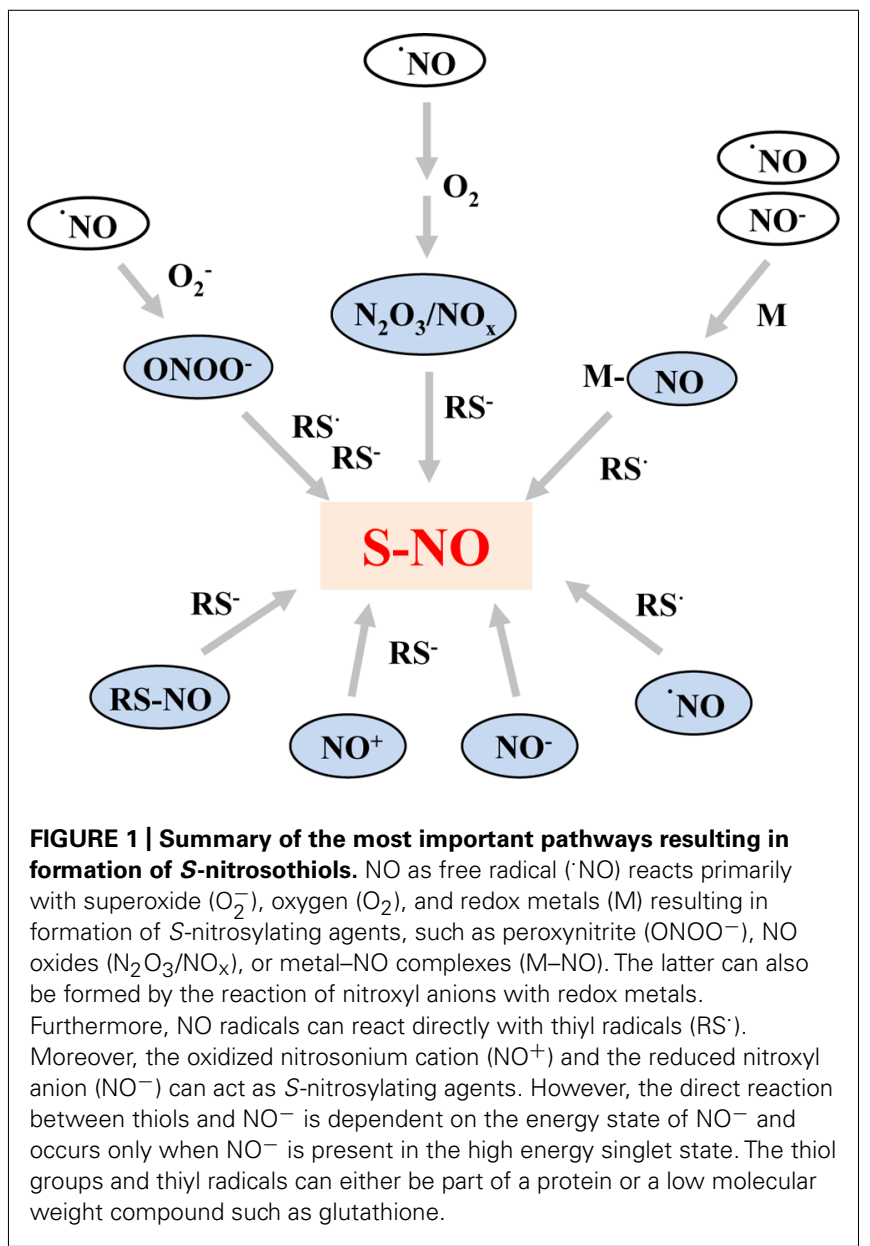

limitation of this mechanism is that nitrosonium is unstable in water, immediately hydrolyzing to nitrite. Therefore, the thiol must be in the immediate vicinity of the source of $\mathrm{NO}^{+}$(Kettenhofen et al., 2007). $\mathrm{N}_{2} \mathrm{O}_{3}$ is generally considered as a nitrosylating agent that can directly mediate thiol nitrosylation (Wink et al., 1994; Goldstein et al., 1996) attacking the reduced (nucleophilic) thiolate anion $\left(\mathrm{RS}^{-}\right)$to yield the $S$-nitrosylated product and nitrite. To generate $\mathrm{N}_{2} \mathrm{O}_{3}$, $\mathrm{NO}$ must be oxidized to $\mathrm{NO}_{2}$ by oxygen, which combines with $\mathrm{NO}$ to form $\mathrm{N}_{2} \mathrm{O}_{3}$. This aerobic formation of $\mathrm{N}_{2} \mathrm{O}_{3}$ depends on the concentration of available NO and $\mathrm{O}_{2}$, because this reaction is of second order in $\mathrm{NO}$ and of first order in $\mathrm{O}_{2}$ (Goldstein et al., 1996), and consequently very slow at biological concentrations of NO. It has been suggested that hydrophobic areas in membranes and proteins could increase the local concentration of both $\mathrm{NO}$ and $\mathrm{O}_{2}$ to accelerate this reaction (Nedospasov et al., 2000). However, Keszler et al. (2010) have recently reported contradictory results with the conclusion that protein hydrophobic environments do not enhance $S$-nitrosylation.

$\mathrm{N}_{2} \mathrm{O}_{3}$ could also be formed from the condensation of nitrous acid $\left(\mathrm{HNO}_{2}\right.$; Guikema et al., 2005). The $\mathrm{p} K_{\mathrm{a}}$ of $\mathrm{HNO}_{2}$ is approximately 3.4, at higher $\mathrm{pH}$ values $\mathrm{HNO}_{2}$ dissociates into nitrite $\left(\mathrm{NO}_{2}^{-}\right)$. Since $\mathrm{N}_{2} \mathrm{O}_{3}$ formation from $\mathrm{HNO}_{2}$ can occur only at low acidic $\mathrm{pH}$, the physiological relevance to 
produce RSNO on this way at neutral $\mathrm{pH}$ is still questionable. However, the apoplast of plants is acidic and might be mediating $\mathrm{pH}$-dependent synthesis of $\mathrm{N}_{2} \mathrm{O}_{3}$, and it was indeed reported that $\mathrm{NO}$ could be produced from nitrite in an acidified apoplast (Bethke et al., 2004).

\section{RADICAL-MEDIATED PATHWAY OF $\boldsymbol{S}$-NITROSYLATION}

Radicals play an important role in mediating cellular signaling processes during stress responses. The direct combination of ' $\mathrm{NO}$ and thiol results in putative intermediate radicals ( $\mathrm{RSN} \cdot \mathrm{OH})$, which in the presence of an electron acceptor get oxidized to $S$-nitrosothiols and superoxide (Gow et al., 1997). However, the major radical-radical combination reaction is the addition of ${ }^{\circ} \mathrm{NO}$ to a thiyl radical (RS ${ }^{*}$ ) to form $S$-nitrosothiols. Rate measurements have demonstrated that such a radical combination reaction is extremely fast (Madej et al., 2008). One-electron oxidation of ' NO yields $\mathrm{NO}_{2}$, which can oxidize thiols to thiyl radicals (Jourd'heuil et al., 2003; Keszler et al., 2010). In addition, $\mathrm{ONOO}^{-}$, the product of ' $\mathrm{NO}$ and superoxide $\left(\mathrm{O}_{2}^{-}\right)$, can form $S$-nitrosothiols either directly with thiolate anion ( $\mathrm{RS}^{-}$; van der Vliet et al., 1998) or through thiyl radicals (Goldstein et al., 1996; Keszler et al., 2010). So, any mechanism or cellular processes that could enhance RS formation, such as increased superoxide formation or the action of peroxidases, has the potential to generate $S$-nitrosothiols, too. However, generation of one-electron oxidants in general requires oxygen, although some data indicate that under certain conditions cellular RSNO formation can occur without $\mathrm{O}_{2}$ (Bosworth et al., 2009). It was recently shown that endogenous $S$-nitrosylation during anaerobic respiration is also controlled by the transcription factor OxyR, previously thought to operate only under aerobic conditions (Seth et al., 2012).

\section{METAL-CATALYZED SNO FORMATION}

Redox-active metal ions can catalyze many of the above mentioned reactions of $S$-nitrosothiol formation. The main sites of action of NO are heme groups and other metal groups like those in sGC, cytochrome $c$ oxidase, or hemoglobins (Brandish et al., 1998; Sarti et al., 2000). Proteins with iron-containing prosthetic groups show the fastest reactions with NO. Iron and NO can take part in reversible electron transfer processes depending on the redox environment. Ferric irons $\left(\mathrm{Fe}^{3+}\right)$ can accept electrons from radical $\mathrm{NO}$ resulting in the formation of ferrous $\left(\mathrm{Fe}^{2+}\right)$ and $\mathrm{NO}^{+}$ions, whereas $\mathrm{Fe}^{2+}$ can donate electrons to radical $\mathrm{NO}$ to form $\mathrm{Fe}^{3+}$ and $\mathrm{NO}^{-}$(Graziano and Lamattina, 2005). There is evidence that copper and iron ions are able to generate $S$-nitrosothiols via one-electron oxidation of thiols to thiyl radicals or by the formation of $\mathrm{NO} /$ metal complexes (Vanin et al., 1997; Stubauer et al., 1999). Fe ${ }^{2+}$, NO, and low molecular weight thiols can form metal containing $S$-nitrosothiols in vivo called dinitrosyl iron complexes (Mulsch et al., 1993; Shumaev et al., 2008). These complexes are considered endogenous NO carriers like low molecular weight nitrosothiols. They have been shown to transfer $\mathrm{NO}$ to the metal-centers of metalloproteins and/or can donate $\mathrm{NO}^{+}$equivalents to thiol groups to form RSNO (Bosworth et al., 2009). It was recently shown that increased NO levels in plants elevate the levels of nitrosyl-iron complexes (Simontacchi et al., 2012).

\section{TRANS-NITROSYLATION}

Trans-nitrosylation is presumably the most important reaction of an $S$-nitrosothiol inside a cell (Arnelle and Stamler, 1995). In addition to direct modification of thiol groups by $\mathrm{NO}$ equivalents, both $S$-nitrosocysteine and $S$-nitrosylated proteins can directly transfer their nitrosyl moiety to acceptor cysteine thiols (Cys-to-Cys transfer). This reversible reaction involves the nucleophilic attack of a thiolate anion $\left(\mathrm{RS}^{-}\right)$of the acceptor protein on the nitroso nitrogen of the donor molecule. There is evidence that not all of the protein thiols are modified by trans-nitrosylation, and some thiols in an individual protein are preferentially $S$-nitrosylated. Nitrosylases can enzymatically mediate trans-nitrosylation, but examples of trans-nitrosylation catalyzed by metalloproteins (metal-to-Cys transfer) also exist (Anand and Stamler, 2012).

$S$-nitrosoglutathione is the major physiological NO donor among the low molecular weight $S$-nitrosothiols, and it is known for its ability to mediate trans-nitrosylation (Dahm et al., 2006). This is the reason why GSNO is the most commonly used NO donor in proteome-wide studies in animals and plants. Furthermore, the emerging role of trans-nitrosylation between cellular proteins has been revealed as an important mechanism in cell signaling pathways (Nakamura and Lipton, 2013).

\section{DETECTION AND IDENTIFICATION OF $S$-NITROSYLATED PROTEINS}

Proteomic analyses of $S$-nitrosothiols generated in vivo are usually a challenge due to the low level, dynamic, and unstable features of $S$-nitrosylation. Nitrosothiols undergo photolytic degradation (Singh et al., 1996) and are reduced by cytosolic reducing agents (ascorbate, glutathione) or by metals (Smith and Dasgupta, 2000) in biological system. This can explain that most of the published studies on $S$-nitrosylated proteins have relied on exogenous treatments with NO or NO donors, which increase the total intracellular RSNO pool to intensify the effect of NO. The development of new techniques for the enrichment and identification of $S$-nitrosylated proteins and mapping of sites of $S$-nitrosylation (SNO-sites) have led to an increasing number of results in this field over the last 10 years.

Various assays with goal-specific modifications have been developed for the characterization, identification, and quantification of S-nitrosylated proteins (Torta et al., 2008; Foster, 2012; Liu et al., 2012). Most of the work has used indirect methods, measuring free NO levels after cleavage of SNO bonds or replacing the original nitrosothiols with another detectable tag (BST). The alternative direct detections of NO-modified thiols by MS or X-ray crystallography have been predominantly applied to the characterization of isolated proteins.

\section{IDENTIFICATION OF SNO SITES}

The most commonly used indirect method to detect $S$-nitrosylated proteins is a BST mentioned above. For a large-scale proteomics analysis, Gross and colleagues have improved the BST technique now called SNO site identification (SNOSID; Hao et al., 2006). In this approach, the proteins are digested with trypsin after labeling of nitrosylated groups with biotin, and the resulting peptides are affinity-purified. The purified peptides are then eluted and analyzed by liquid chromatography-tandem MS (LC-MS/MS), 
allowing high-throughput identification of the modified cysteines. In another study, the SNOSID has been modified to improve the LC/MS performance to optimize a detergent-free protocol by using urea as a denaturant in the first step of BST from HeLa cells in the presence or absence of GSNO (Han and Chen, 2008). Greco et al. (2006) have reported that using formic acid instead of a reducing agent to elute biotinylated peptides from avidin beads increases the specificity of the detected SNO sites, because in this way the biotin-HPDP adduct is still present on the eluted peptides.

The SNO-resin assisted capture methodology substitutes a thiol-active resin (e.g., thiopropyl sepharose) for biotin-HPDP (Forrester etal., 2009b). This method simplifies SNOSID such that the captured proteins are proteolyzed on resin, and SNO-sitecontaining peptides are eluted with reductant and identified by LC-MS/MS. The elimination of biotin removal and avidin-based enrichment steps appears to improve the sensitivity for detection of high-mass SNO-proteins.

Another way of modification of BST is the His-tag switch method, where the SNO-bond is specifically replaced by a Histag containing peptide (Camerini et al., 2007). The advantage of this new labeling peptide is that it binds irreversibly to the reduced cysteines, maintaining the proteins label through all the purification steps. This approach was applied to the analysis of neuronal cytosolic proteins from rat cerebral cortex and $28 \mathrm{~S}$-nitrosylated sites were identified by MS.

To circumvent the ascorbate reduction step in the BST, phenylmercury compounds were alternatively used to react directly with $S$-nitrosocysteine forming a relative stable thiolmercury bond (Doulias et al., 2010). In this study, an organomercury resin was synthesized for solid-phase capturing of $S$ nitrosylated proteins/peptides. A different approach used a newly designed phenylmercury-polyethylene glycol-biotin compound for biotin-avidin affinity purification. In addition to the mercurybased SNO reaction, Faccenda et al. (2010) have described a gold nanoparticle that can be used to directly enrich $S$-nitrosylated proteins. It was demonstrated that thiols and thioethers have a higher affinity for gold than other functional groups in proteins. Thus, these particles may have the potential to discriminate the disulfide bond and other cysteine modifications from the $S$-nitrosylated ones.

\section{SNO-SITE QUANTIFICATION}

Understanding the role of NO modifications under various physiological and pathological conditions requires quantification of the dynamic changes of protein $S$-nitrosylation. Relative levels of SNO-proteins can be determined using Western blotting and densitometry or by fluorescence-based quantification using either thiol-reactive fluorophores (Kettenhofen et al., 2008; Tello et al., 2009) or fluorescent secondary antibodies (Foster et al., 2009). The fluorescence labeling of the modified thiols by two different fluorophores ( $\mathrm{Cy} 3$ and $\mathrm{Cy} 5$ ) from control and treated samples in combination with a 2D difference gel electrophoresis technique allows the simultaneous identification of a protein from a single spot and the quantification of the relative level of thiol modification (Kettenhofen et al., 2007). Further modification for specifically labeling, detecting, and quantifying protein $S$-nitrosylation is reported using a fluorescence saturation labeling technique and unique concepts for measuring changes in $S$-nitrosylation status relative to protein abundance are introduced (Wiktorowicz et al., 2011).

Mass spectrometry has also been employed for relative quantification of SNO-proteins. The S-nitrosothiol capture method adapts the isotope-coded affinity tag technique (Gygi et al., 1999), which utilizes light and heavy isotope-labeled (12C and 13C, respectively) thiol biotinylating agents in conjunction with LCMS/MS to identify and quantify expression level differences of SNO-sites between two conditions (Paige et al., 2008; Fares et al., 2011). Huang and Chen (2010) reported a combination of isotopebased technique and irreversible biotinylation procedure using a biotin-maleimide tag instead of biotin-HPDP for a quantitative proteomic approach of $S$-nitrosylation. Alternatively, stable isotope labeling of amino acids in cell culture, which employs light and heavy isotope-labeled Arg and/or Lys for relative quantification of tryptic peptides, has been combined with detergent-free BST and LC-MS/MS for endogenous SNO quantifications (Zhou et al., 2010; Torta and Bachi, 2012). The major advantage of this labeling method is that samples can be mixed before the blocking and purification steps thus reducing the errors deriving from sample preparations and providing a more accurate quantification ratio.

\section{STRUCTURAL FEATURES OF CYSTEINE $S$-NITROSYLATION SITES}

Most proteins possess cysteine residues, but the affinity of this amino acid residue to NO can be very different. Despite of proteome-wide studies and $S$-nitrosylation motif screens, up to now, there is no general rule which could explain which cysteine would be amenable to nitrosylation. In the beginning, the linear sequence of $S$-nitrosylated proteins was analyzed searching for consensus motifs. The analysis of NO transfer in hemoglobin provided the basis for an acid-base motif for protein $S$-nitrosylation and denitrosylation (Stamler et al., 1997). The acid-base motif is comprised of flanking acidic $(\mathrm{D}, \mathrm{E})$ and basic $(\mathrm{R}, \mathrm{H}, \mathrm{K})$ residues embracing the reactive thiol cysteine sites ([KRHDE]-C-[DE]). These can suppress or favor, respectively, the formation of nucleophilic thiolate $\left(\mathrm{RS}^{-}\right)$through electrostatic interactions. This motif has been shown to be predictive in a number (but not all) of cases and the general feature of acid-base motifs is still object of intense discussion since then. Moreover, a GSNO binding motif has been described ([HKR]-C-[hydrophobic]X[DE]) (Hess et al., 2005). In Arabidopsis S-adenosylmethionine synthetase 1 such a GSNO binding motif for trans-S-nitrosylation is present, embracing $\mathrm{C}_{114}$. $S$-nitrosylation of this cysteine residue is responsible for inhibition of the activity of $S$-adenosylmethionine synthetase 1 (Lindermayr et al., 2006). Another factor suggested to play a role in $S$-nitrosylation is a low $\mathrm{p} K_{\mathrm{a}}$ of cysteine, for example in the case of metalloproteins, where transition metal coordination decreases thiol $\mathrm{p} K_{\mathrm{a}}$ (Hess et al., 2005). It has been shown that the interaction between Cys thiols and aromatic side chains in its vicinity promotes formation of a thiolate anion, which enhances the possibility of NO modification (Britto et al., 2002). S-nitrosylated cysteines were also found in hydrophobic pockets of proteins (Greco et al., 2006), which can sequester or stabilize radicals to 
form S-nitrosylating species (Nedospasov et al., 2000). With the development of different methods and proteomic approaches for detection and identification of $S$-nitrosylated sites from complex biological mixtures an increasing number of identified SNO sites have allowed to analyze the precise environments of the modified cysteines. A proteomic approach using selective peptide capturing from human vascular smooth muscle cells revealed 18 proteins with $S$-nitrosylated cysteines and the presence of acid-base motifs, as well as hydrophobic motifs surrounding the identified cysteine residues (Greco et al., 2006). In contrast, using the SNOSID method to identify $68 \mathrm{SNO}$-Cys sites from rat cerebellum protein samples, Hao et al. (2006) failed to find any evidence for a linear Cys-flanking motif with the help of a machine learning approach. They suggested that key determinants of NO-targeting are likely to be encoded in the 3D cysteine environment. Searches of Arabidopsis protein databases with a degenerate SNO motif proposed by Stamler [GSTCYNQ]-[KRHDE]-C-[DE] have yielded a few hundred hits which include proteins related to cell signaling, transport, cell cycle, and metabolism processes (Wilson et al., 2008). However, no protein of this list has so far been identified to be $S$-nitrosylated in vivo. A novel proteomic approach using sitespecific high-throughput identification of protein $S$-nitrosylation from breast cancer cells revealed a consensus I-C hydrophobic motif center flanked by acidic $(\mathrm{D} / \mathrm{E})$ and basic $(\mathrm{R} / \mathrm{K})$ residues (Liu et al., 2010). This result provided direct support for the presence of the acid-base motif and the importance of a hydrophobic environment in the vicinity of $S$-nitrosylated cysteine (Hess et al., 2001). Marino and Gladyshev (2010) have used a bioinformatic approach to analyze general features of $S$-nitrosylation. A data set of 55 non-redundant proteins containing $70 \mathrm{SNO}-\mathrm{Cys}$ sites was created manually based on in vitro studies available from literature reports. They included only proteins with established crystal or NMR structures, or proteins that could be modeled by standard homology modeling approaches. They established that the proximal acid-base motif, cysteine $\mathrm{p} K_{\mathrm{a}}$, sulfur atom exposure, and cysteine hydrophobicity in the vicinity of the modified cysteine did not define the specificity of $S$-nitrosylation. Instead, they proposed a revised acid-base motif, which was located more distantly with regard to the Cys ( $8 \AA$ ) and with its charged groups exposed (solvent accessible). Charged residues have a strong influence on the electrostatic potential distribution of proteins, which is a crucial feature for protein-protein interactions. They hypothesize that the modified acid-base motif plays a role in protein-protein interactions resulting in trans-nitrosylation of target proteins rather than in the direct activation of cysteine to form thiolate anions for further S-nitrosylation (Marino and Gladyshev, 2010). Doulias et al. (2010) reported an endogenous $S$-nitrosoproteome study from WT mouse liver with 328 modified Cys sites in 192 proteins suggesting multiple mechanisms for selective site-directed $S$-nitrosylation. Structural analysis of $S$-nitrosylated cysteines revealed that SNO sites were equally distributed in hydrophobic and hydrophilic areas of proteins with an average predicted $\mathrm{p} K_{\mathrm{a}}$ of 10.01 . Furthermore, $70 \%$ of the $S$-nitrosylated cysteine residues were surrounded by negatively or positively charged amino acids within a distance of $6 \AA$. Based on the presence of modified cysteine residues in highly exposed areas of proteins and in proximity to charged amino acids they suggest a protein or small molecule (like GSNO) trans-nitrosylation assisted mechanism (Doulias et al., 2010). Moreover, 13 modified cysteines were coordinated with metals and 15 metalloproteins were endogenously modified supporting metal-catalyzed $S$-nitrosylation mechanisms, too. Proteomics investigation of endogenous S-nitrosylation in Arabidopsis cell suspensions yielded 53 SNOSIDs (Fares et al., 2011). Structural studies of S-nitrosylated cysteines and their vicinities have shown no clear over-representation of acid-base motifs, only three apolar residues (A-Ala, G-Gly, I-Ile) were found to be significantly enriched in the flanking regions of the modified cysteines.

\section{COMPUTATIONAL PREDICTION OF S-NITROSYLATION SITES}

However, although much effort was paid to find consensus structural features to describe the specificity of $S$-nitrosylation based on a large number of datasets from a different proteomic studies, the prediction of $S$-nitrosylation sites in proteins still remains a great challenge. In the case of other post-translational modifications, computational approaches have been shown to be able to rapidly generate helpful information to stimulate further experimental verification. Xue etal. (2010) have first developed the software called GPS-SNO 1.0 for S-nitrosylation site prediction. They have improved their previously developed algorithm for the prediction of kinase-specific phosphorylation sites and released the GPS 3.0 algorithm (group-based prediction system) for GPSSNO. The training set for the new algorithm was obtained from the literature and from public databases with 504 experimentally verified S-nitrosylation sites in 327 unique proteins. The prediction performance of GPS 3.0 yielded an accuracy of $75.80 \%$, a sensitivity of $53.57 \%$ and a specificity of $80.14 \%$ under low threshold condition. GPS-SNO 1.0 was applied on a test set of 485 potentially $S$-nitrosylated substrates collected from PubMed. The SNO site prediction resulted in at least one potential $S$-nitrosylation site per protein of $74 \%$ of the test proteins, which could be a starting point for further experimental verifications. The online service and local packages of GPS-SNO 1.0 are freely available at http://sno.biocuckoo.org/.

Another systematic informatics investigation on the $S$ nitrosylation substrate specificity was reported by Lee etal. (2011). The study was based on 586 S-nitrosylation sites identified experimentally from mouse endothelial cells (Chen et al., 2010). Site-specific characterization including structural factors such as the flanking amino acids composition, the accessible surface area and physicochemical properties was needed to distinguish the $S$-nitrosylation sites from non-S-nitrosylation sites. Due to the difficulty to obtain the conserved motifs by conventional motif analysis, maximal dependence decomposition (MDD) was applied to obtain statistically significant conserved motifs to cluster all sequences of $S$-nitrosylation sites into 11 subgroups. Support vector machine (SVM) was applied to generate predictive model for each MDD-clustered motif. According to fivefold cross-validation, the MDD-clustered SVMs could achieve an accuracy of 0.902 , and provided a promising performance on an independent test set (experimental S-nitrosylation data from GPS-SNO). The models obtained with the MDD clustering method were applied to implement a novel web-based tool, named SNOSite for identifying cysteine S-nitrosylation. SNOSite can be accessed via a web interface, and is freely available 
at http://csb.cse.yzu.edu.tw/SNOSite/. Databases of cysteine $S$-nitrosylation have also been established to collect experimentally determined SNO sites. The dbSNO database was created to integrate all available datasets and to provide their structural analysis (Lee etal., 2012). Up to April 15, 2012, the dbSNO has manually accumulated $>3000$ experimentally verified S-nitrosylated peptides from 219 research articles using a text mining approach. The dbSNO database provides structural and functional analyses, including the motifs of substrate sites, solvent accessibility, protein secondary and tertiary structures, protein domains, and gene ontology. The dbSNO is freely accessible via http://dbSNO.mbc.nctu.edu.tw. Another database named SNObase released nearly at the same time has collected $S$-nitrosylation targets extracted from the literature up to June 1, 2012 (Zhang et al., 2012). SNObase contains 2561 instances, and provides information about $S$-nitrosylation targets, sites, biological model, related diseases, trends of $S$-nitrosylation level, and effects of $S$-nitrosylation on protein function. $S$-nitrosylation targets from plants represent $6.4 \%$ of the total database, whilst the majority are human (41.5\%), and mouse (32.6\%). SNObase is freely available at http://www.nitrosation.org.

Recently another predictor, called iSNO-PseAAC (pseudo amino acid composition), has been published for identifying the SNO sites in proteins by incorporating the position-specific amino acid propensity into the general form of PseAAC (Xu et al., 2013). The benchmark dataset was derived from the dbSNO database. To reduce the redundancy, 438 proteins were selected (with 731 experimentally verified SNO sites) in which none had $\geq 40 \%$ pairwise sequence identity to any other. The overall cross-validation success rate in identifying nitrosylated proteins on an independent dataset was over 90\%. A web-server for iSNO-PseAAC was established at http://app.aporc.org/iSNO-PseAAC/.

Table 2 | Computational prediction of $S$-nitrosylation sites from 10 experimentally identified $S$-nitrosylated proteins from Arabidopsis thaliana using GPS-SNO, SNOSite, and iSNO-PseAAC programs.

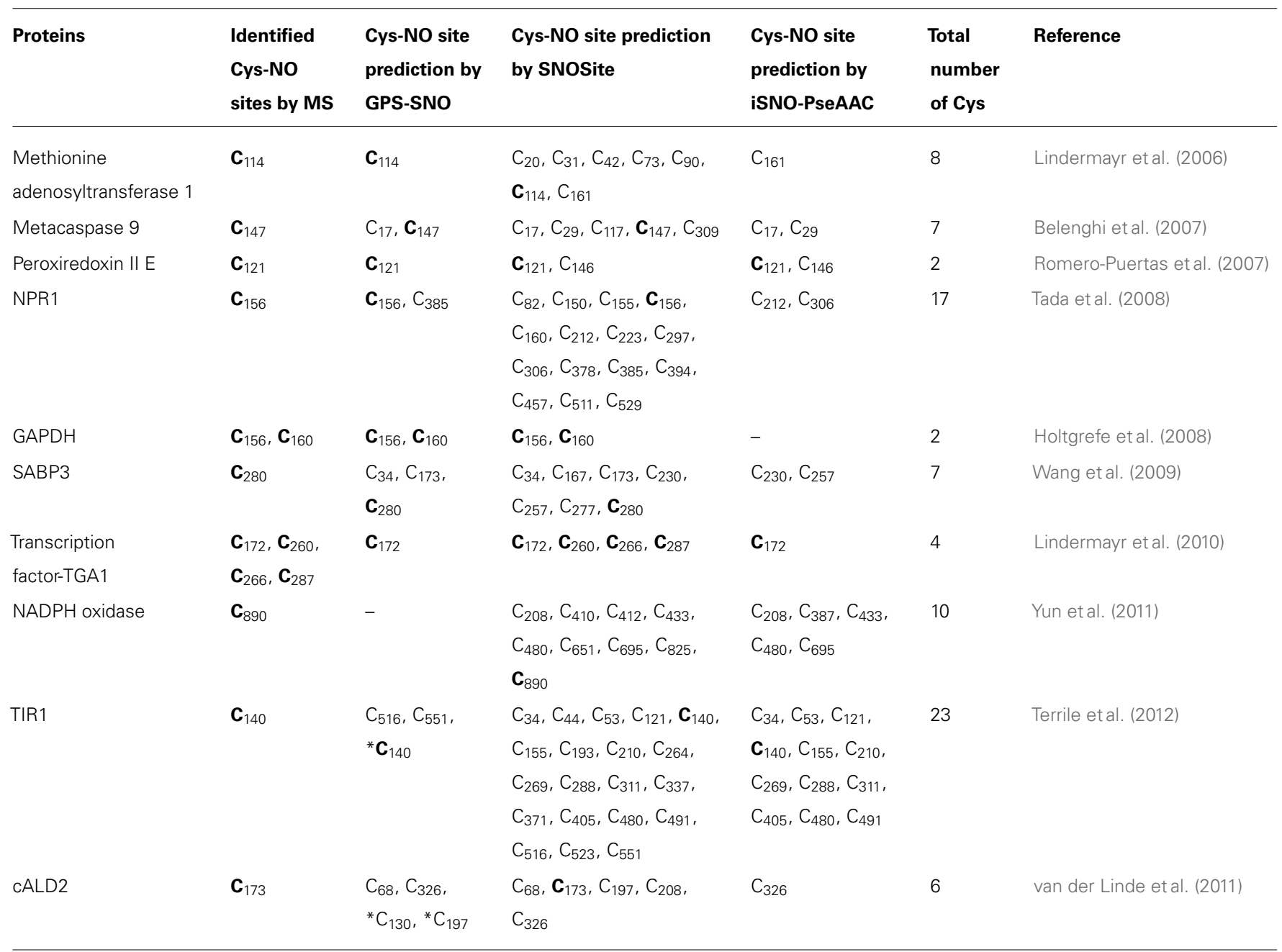


We have chosen 10 known S-nitrosylated proteins from Arabidopsis thaliana to compare the prediction efficiency of the available SNO site prediction programs GPS-SNO, SNOSite, and iSNO-PseAAC (Table 2). The selected Arabidopsis proteins have been analyzed in details for cysteine modifications and $S$ nitrosylation sites have been confirmed by MS. Table 2 shows that all of the computational programs have predicted SNO sites to the selected proteins with different efficiency. The overall success rate (how many proteins were predicted containing at least one SNO site) was 100\% using SNOsite and 90\% in the case of both GPS-SNO and iSNO-PseAAC programs. However, the prediction specificities were quite different using the three programs. The SNOSite has predicted a possibility to be modified by NO almost to all of the available cysteines, whereas the GPS-SNO predicted fewer SNO sites with the highest matching to the verified sites. The prediction by iSNO-PseAAC has resulted in the lowest specificity to the identified SNO sites. The GPS-SNO program seems to be the most reliable one for predicting putative $S$-nitrosylation sites providing a good base for future experimental confirmations of proteins with unknown positions of modification.

\section{REFERENCES}

Abat, J. K., Mattoo, A. K., and Deswal, R. (2008). S-nitrosylated proteins of a medicinal CAM plant Kalanchoe pinnata- ribulose-1,5-bisphosphate carboxylase/oxygenase activity targeted for inhibition. FEBS J. 275, 2862 2872.

Alderton, W. K., Cooper, C. E., and Knowles, R. G. (2001). Nitric oxide synthases: structure, function and inhibition. Biochem. J. 357, 593-615.

Anand, P., and Stamler, J. S. (2012). Enzymatic mechanisms regulating protein $S$-nitrosylation: implications in health and disease. J. Mol. Med. (Berl.) 90, 233-244.

Arnelle, D. R., and Stamler, J. S. (1995). $\mathrm{NO}+, \mathrm{NO}$, and NO- donation by $S$-nitrosothiols: implications for regulation of physiological functions by $S$-nitrosylation and acceleration of disulfide formation. Arch. Biochem. Biophys. 318, 279-285.

Astier, J., Kulik, A., Koen, E., BessonBard, A., Bourque, S., Jeandroz, S., et al. (2012). Protein $S$-nitrosylation: what's going on in plants? Free Radic. Biol. Med. 53, 1101-1110.

Astier, J., and Lindermayr, C. (2012). Nitric oxide-dependent posttranslational modification in plants: an update. Int. J. Mol. Sci. 13, 1519315208.

Belenghi, B., Romero-Puertas, M. C., Vercammen, D., Brackenier, A., Inze, D., Delledonne, M., et al. (2007). Metacaspase activity of Arabidopsis thaliana is regulated by $S$ nitrosylation of a critical cysteine residue. J. Biol. Chem. 282, 13521358.
Benhar, M., Forrester, M. T., and Stamler, J. S. (2009). Protein denitrosylation: enzymatic mechanisms and cellular functions. Nat. Rev. Mol. Cell Biol. 10, 721-732.

Bethke, P. C., Badger, M. R., and Jones, R. L. (2004). Apoplastic synthesis of nitric oxide by plant tissues. Plant Cell 16, 332-341.

Bethke, P. C., Libourel, I. G., and Jones, R. L. (2006). Nitric oxide reduces seed dormancy in Arabidopsis. J. Exp. Bot. 57, 517-526.

Bosworth, C. A., Toledo, J. C. Jr., Zmijewski, J. W., Li, Q., and Lancaster, J. R. (2009). Dinitrosyliron complexes and the mechanism(s) of cellular protein nitrosothiol formation from nitric oxide. Proc. Natl. Acad. Sci. U.S.A. 106, 4671-4676.

Brandish, P. E., Buechler, W., and Marletta, M. A. (1998). Regeneration of the ferrous heme of soluble guanylate cyclase from the nitric oxide complex: acceleration by thiols and oxyhemoglobin. Biochemistry 37, 16898-16907.

Britto, P. J., Knipling, L., and Wolff, J. (2002). The local electrostatic environment determines cysteine reactivity of tubulin. J. Biol. Chem. 277, 29018-29027.

Broniowska, K. A., and Hogg, N. (2012). The chemical biology of $S$ nitrosothiols. Antioxid. Redox Signal. 17, 969-980.

Camejo, D., Romero-Puertas, M. D., Rodriguez-Serrano, M., Sandalio, L. M., Lazaro, J. J., Jimenez, A., et al. (2012). Salinity-induced changes in $S$-nitrosylation of pea mitochondrial proteins. J. Proteomics $79 \mathrm{C}$ 87-99.

\section{CONCLUSION}

Protein $S$-nitrosylation, as a redox-based post-translational modification plays an essential role in regulating a number of fundamental and pathological processes in animals and plants. However, many questions still remain in terms of NO production and exact signaling routes, through which NO influences a broadspectrum of inter- and intracellular signaling in plants. Rapid progress has been made in development and application of proteomic approaches to identify and analyze $S$-nitrosylation in the plant field. Future research needs to focus on characterization of the biological functions of $S$-nitrosylated proteins, e.g., the impact of $S$-nitrosylation on enzyme activities, protein translocation, and protein interaction networks. Moreover, individual $S$-nitrosylation site have to be characterized using a combination of computational predictions and experimental verifications to understand the molecular mechanism of $S$-nitrosylation.

\section{ACKNOWLEDGMENT}

We thank Dr. Günther Bahnweg for accurately editing this manuscript.

Camerini, S., Polci, M. L., Restuccia, U., Usuelli, V., Malgaroli, A. and Bachi, A. (2007). A novel approach to identify proteins modified by nitric oxide: the HIS-TAG switch method. J. Proteome Res. 6, 3224-3231.

Cary, S. P., Winger, J. A., Derbyshire, E. R., and Marletta, M. A. (2006). Nitric oxide signaling: no longer simply on or off. Trends Biochem. Sci. 31, 231-239.

Chen, Y. J., Ku, W. C., Lin, P. Y., Chou, H. C., Khoo, K. H., and Chen, Y. J. (2010). S-alkylating labeling strategy for site-specific identification of the $S$-nitrosoproteome. J. Proteome Res. 9, 6417-6439.

Corpas, F. J., Barroso, J. B., Carreras, A., Quiros, M., Leon, A. M., RomeroPuertas, M. C., et al. (2004). Cellular and subcellular localization of endogenous nitric oxide in young and senescent pea plants. Plant Physiol. 136, 2722-2733.

Corpas, F. J., Leterrier, M., Valderrama, R., Airaki, M., Chaki, M., Palma, J. M., et al. (2011). Nitric oxide imbalance provokes a nitrosative response in plants under abiotic stress. Plant Sci. 181, 604-611.

Correa-Aragunde, N., Graziano, M., and Lamattina, L. (2004). Nitric oxide plays a central role in determining lateral root development in tomato. Planta 218, 900-905.

Dahm, C. C., Moore, K., and Murphy, M. P. (2006). Persistent Snitrosation of complex I and other mitochondrial membrane proteins by $S$-nitrosothiols but not nitric oxide or peroxynitrite: implications for the interaction of nitric oxide with mitochondria. J. Biol. Chem. 281, 1005610065.

Doulias, P. T., Greene, J. L., Greco, T. M., Tenopoulou, M., Seeholzer, S. H., Dunbrack, R. L., et al. (2010). Structural profiling of endogenous $S$-nitrosocysteine residues reveals unique features that accommodate diverse mechanisms for protein $S$ nitrosylation. Proc. Natl. Acad. Sci. U.S.A. 107, 16958-16963.

Durner, J., Wendehenne, D., and Klessig, D. F. (1998). Defense gene induction in tobacco by nitric oxide, cyclic GMP, and cyclic ADP-ribose. Proc. Natl. Acad. Sci. U.S.A. 95, 10328-10333.

Faccenda, A., Bonham, C. A., Vacratsis, P. O., Zhang, X., and Mutus, B. (2010). Gold nanoparticle enrichment method for identifying $S$ nitrosylation and $S$-glutathionylation sites in proteins. J. Am. Chem. Soc. 132, 11392-11394.

Fares, A., Rossignol, M., and Peltier, J. B. (2011). Proteomics investigation of endogenous $S$-nitrosylation in Arabidopsis. Biochem. Biophys. Res. Commun. 416, 331-336.

Ford, P. C. (2010). Reactions of NO and nitrite with heme models and proteins. Inorg. Chem. 49, 6226-6239.

Forrester, M. T., Foster, M. W., Benhar, M., and Stamler, J. S. (2009a). Detection of protein $S$-nitrosylation with the biotin-switch technique. Free Radic. Biol. Med. 46, 119-126.

Forrester, M. T., Thompson, J. W., Foster, M. W., Nogueira, L., Moseley, M. A., and Stamler, J. S. (2009b). Proteomic analysis of $S$-nitrosylation and denitrosylation by resin-assisted capture. Nat. Biotechnol. 27, 557-559. 
Forrester, M. T., Foster, M. W., and Stamler, J. S. (2007). Assessment and application of the biotin switch technique for examining protein $S$ nitrosylation under conditions of pharmacologically induced oxidative stress. J. Biol. Chem. 282, 1397713983.

Foster, M. W. (2012). Methodologies for the characterization, identification and quantification of $S$-nitrosylated proteins. Biochim. Biophys. Acta 1820, 675-683.

Foster, M. W., Forrester, M. T., and Stamler, J. S. (2009). A protein microarray-based analysis of $S$ nitrosylation. Proc. Natl. Acad. Sci. U.S.A. 106, 18948-18953.

Gaupels, F., Kuruthukulangarakoola, G. T., and Durner, J. (2011). Upstream and downstream signals of nitric oxide in pathogen defence. Curr. Opin. Plant Biol. 14, 707-714.

Goldstein, S., Squadrito, G. L., Pryor, W. A., and Czapski, G. (1996). Direct and indirect oxidations by peroxynitrite, neither involving the hydroxyl radical. Free Radic. Biol. Med. 21, 965-974.

Gow, A. J., Buerk, D. G., and Ischiropoulos, H. (1997). A novel reaction mechanism for the formation of $S$ nitrosothiol in vivo. J. Biol. Chem. 272, 2841-2845.

Graziano, M., and Lamattina, L. (2005). Nitric oxide and iron in plants: an emerging and converging story. Trends Plant Sci. 10, 4-8.

Greco, T. M., Hodara, R., Parastatidis, I., Heijnen, H. F., Dennehy, M. K., Liebler, D. C., et al. (2006). Identification of $S$-nitrosylation motifs by site-specific mapping of the $S$ nitrosocysteine proteome in human vascular smooth muscle cells. Proc. Natl. Acad. Sci. U.S.A. 103, 7420 7425.

Guikema, B., Lu, Q., and Jourd'heuil, D. (2005). Chemical considerations and biological selectivity of protein nitrosation: implications for NO-mediated signal transduction. Antioxid. Redox Signal. 7, 593-606.

Gygi, S. P., Rist, B., Gerber, S. A., Turecek, F., Gelb, M. H., and Aebersold, R. (1999). Quantitative analysis of complex protein mixtures using isotopecoded affinity tags. Nat. Biotechnol. 17, 994-999.

Han, P., and Chen, C. (2008). Detergent-free biotin switch combined with liquid chromatography/tandem mass spectrometry in the analysis of $S$-nitrosylated proteins. Rapid Commun. Mass Spectrom. 22, 1137-1145.

Hao, G., Derakhshan, B., Shi, L. Campagne, F., and Gross, S.
S. (2006). SNOSID, a proteomic method for identification of cysteine $S$-nitrosylation sites in complex protein mixtures. Proc. Natl. Acad. Sci. U.S.A. 103, 1012-1017.

He, Y., Tang, R. H., Hao, Y., Stevens, R. D., Cook, C. W., Ahn, S. M., et al. (2004). Nitric oxide represses the Arabidopsis floral transition. Science 305, 1968-1971.

Hess, D. T., Matsumoto, A., Kim, S. O., Marshall, H. E., and Stamler J. S. (2005). Protein S-nitrosylation: purview and parameters. Nat. Rev. Mol. Cell Biol. 6, 150-166.

Hess, D. T., Matsumoto, A., Nudelman, R., and Stamler, J. S. (2001). S-nitrosylation: spectrum and specificity. Nat. Cell Biol. 3, E46-E49.

Hess, D. T., and Stamler, J. S (2012). Regulation by $S$-nitrosylation of protein post-translational modification. J. Biol. Chem. 287, 4411-4418.

Holmes, A. J., and Williams, D. L. H. (2000). Reaction of ascorbic acid with $S$-nitrosothiols: clear evidence for two distinct reaction pathways. $J$. Chem. Soc. Perkin Trans. 2, 1639 1644.

Holtgrefe, S., Gohlke, J., Starmann, J., Druce, S., Klocke, S., Altmann, B., et al. (2008). Regulation of plant cytosolic glyceraldehyde 3 phosphate dehydrogenase isoforms by thiol modifications. Physiol. Plant. 133, 211-228.

Huang, B., and Chen, C. (2006) An ascorbate-dependent artifact that interferes with the interpretation of the biotin switch assay. Free Radic. Biol. Med. 41, 562-567.

Huang, B., and Chen, C. (2010). Detection of protein $S$-nitrosation using irreversible biotinylation procedures (IBP). Free Radic. Biol. Med. 49, 447-456.

Ignarro, L. J., Buga, G. M., Wood, K. S., Byrns, R. E., and Chaudhuri, G. (1987). Endothelium-derived relaxing factor produced and released from artery and vein is nitric oxide. Proc. Natl. Acad. Sci. U.S.A. 84 9265-9269.

Jaffrey, S. R., and Snyder, S. H. (2001) The biotin switch method for the detection of $S$-nitrosylated proteins. Sci. STKE 2001, pl1.

Jourd'heuil, D., Jourd'heuil, F. L., and Feelisch, M. (2003). Oxidation and nitrosation of thiols at low micromolar exposure to nitric oxide. Evidence for a free radical mechanism. J. Biol. Chem. 278, 15720-15726.

Kato, H., Takemoto, D., and Kawakita K. (2012). Proteomic analysis of $S$ nitrosylated proteins in potato plant.
Physiol Plant. doi: 10.1111/j.13993054.2012.01684.x [Epub ahead of print].

Keszler, A., Zhang, Y., and Hogg, N. (2010). Reaction between nitric oxide, glutathione, and oxygen in the presence and absence of protein: how are $S$-nitrosothiols formed? Free Radic. Biol. Med. 48, 55-64.

Kettenhofen, N. J., Broniowska, K. A., Keszler, A., Zhang, Y., and Hogg, N. (2007). Proteomic methods for analysis of S-nitrosation. J. Chromatogr. B Analyt. Technol. Biomed. Life Sci. 851, 152-159.

Kettenhofen, N. J., Wang, X., Gladwin, M. T., and Hogg, N. (2008). Ingel detection of $S$-nitrosated proteins using fluorescence methods. Methods Enzymol. 441, 53-71.

Klessig, D. F., Durner, J., Noad, R. Navarre, D. A., Wendehenne, D. Kumar, D., et al. (2000). Nitric oxide and salicylic acid signaling in plant defense. Proc. Natl. Acad. Sci. U.S.A. 97, 8849-8855.

Landino, L. M., Koumas, M. T., Mason, C. E., and Alston, J. A (2006). Ascorbic acid reduction of microtubule protein disulfides and it relevance to protein $S$-nitrosylation assays. Biochem. Biophys. Res. Commun. 340, 347-352.

Lee, T. Y., Chen, Y. J., Lu, C. T., Ching W. C., Teng, Y. C., Huang, H. D., et al. (2012). dbSNO: a database of cysteine $S$-nitrosylation. Bioinformatics 28, 2293-2295.

Lee, T. Y., Chen, Y. J., Lu, T. C. Huang, H. D., and Chen, Y. J. (2011). SNOSite: exploiting maximal dependence decomposition to identify cysteine $S$-nitrosylation with substrate site specificity. PLOS ONE 6:e21849. doi: 10.1371/journal.pone.0021849

Leshem, Y. Y., Wills, R. B. H., and Ku, V. V. V. (1998). Evidence for the function of the free radical gas - nitric oxide (NO(center dot)) as an endogenous maturation and senescence regulating factor in higher plants. Plant Physiol. Biochem. 36, 825-833.

Lin, A., Wang, Y., Tang, J., Xue, P., Li, C., Liu, L., et al. (2012). Nitric oxide and protein $S$-nitrosylation are integral to hydrogen peroxide-induced leaf cell death in rice. Plant Physiol. 158, 451-464.

Lindermayr, C., Saalbach, G., Bahnweg, G., and Durner, J. (2006). Differentia inhibition of Arabidopsis methionine adenosyltransferases by protein S-nitrosylation. J. Biol. Chem. 281, 4285-4291.

Lindermayr, C., Saalbach, G., and Durner, J. (2005). Proteomic identification of $S$-nitrosylated proteins in Arabidopsis. Plant Physiol. 137, 921-930.

Lindermayr, C., Sell, S., Muller, B., Leister, D., and Durner, J. (2010). Redox regulation of the NPR1-TGA1 system of Arabidopsis thaliana by nitric oxide. Plant Cell 22, 2894-2907.

Liu, M., Hou, J., Huang, L., Huang, X., Heibeck, T. H., Zhao, R., et al. (2010). Site-specific proteomics approach for study protein $S$-nitrosylation. Anal. Chem. 82, 7160-7168.

Liu, M., Talmadge, J. E., and Ding, S. J. (2012). Development and application of site-specific proteomic approach for study protein $S$ nitrosylation. Amino Acids 42, 15411551.

Ma, W., Smigel, A., Verma, R., and Berkowitz, G. A. (2009). Cyclic nucleotide gated channels and related signaling components in plant innate immunity. Plant Signal. Behav. 4, 277-282.

Madej, E., Folkes, L. K., Wardman, P., Czapski, G., and Goldstein, S. (2008). Thiyl radicals react with nitric oxide to form $S$-nitrosothiols with rate constants near the diffusion-controlled limit. Free Radic. Biol. Med. 44, 2013-2018.

Maldonado-Alconada, A. M., Echevarria-Zomeno, S., Lindermayr, C., Redondo-Lopez, I., Durner, J., and Jorrin-Novo, J. V. (2011). Proteomic analysis of Arabidopsis protein $S$-nitrosylation in response to inoculation with Pseudomonas syringae. Acta Physiol. Plant. 33, 1493-1514.

Marino, S. M., and Gladyshev, V. N. (2010). Structural analysis of cysteine $S$-nitrosylation: a modified acid-based motif and the emerging role of trans-nitrosylation. J. Mol. Biol. 395, 844-859.

Martinez-Atienza, J., Van Ingelgem, C., Roef, L., and Maathuis, F. J. (2007). Plant cyclic nucleotide signalling: facts and fiction. Plant Signal. Behav. 2, 540-543.

Martinez-Ruiz, A., Cadenas, S., and Lamas, S. (2011). Nitric oxide signaling: classical, less classical, and nonclassical mechanisms. Free Radic. Biol. Med. 51, 17-29.

Mulsch, A., Mordvintcev, P. I., Vanin, A. F., and Busse, R. (1993). Formation and release of dinitrosyl iron complexes by endothelial cells. Biochem. Biophys. Res. Commun. 196, 1303 1308.

Nakamura, T., and Lipton, S. A. (2013). Emerging role of protein-protein transnitrosylation in cell signaling pathways. Antioxid. Redox Signal. 18, 239-249. 
Nedospasov, A., Rafikov, R., Beda, N., and Nudler, E. (2000). An autocatalytic mechanism of protein nitrosylation. Proc. Natl. Acad. Sci. U.S.A. 97, 13543-13548.

Neill, S. J., Desikan, R., Clarke, A., and Hancock, J. T. (2002). Nitric oxide is a novel component of abscisic acid signaling in stomatal guard cells. Plant Physiol. 128, 13-16.

Ortega-Galisteo, A. P., RodriguezSerrano, M., Pazmino, D. M., Gupta, D. K., Sandalio, L. M., and RomeroPuertas, M. C. (2012). S-nitrosylated proteins in pea (Pisum sativum L.) leaf peroxisomes: changes under abiotic stress. J. Exp. Bot. 63, 2089-2103.

Pacher, P., Beckman, J. S., and Liaudet, L. (2007). Nitric oxide and peroxynitrite in health and disease. Physiol. Rev. 87, 315-424.

Paige, J. S., Xu, G., Stancevic, B. and Jaffrey, S. R. (2008). Nitrosothiol reactivity profiling identifies $S$ nitrosylated proteins with unexpected stability. Chem. Biol. 15, 13071316.

Palmer, R. M., Ashton, D. S., and Moncada, S. (1988). Vascular endothelial cells synthesize nitric oxide from L-arginine. Nature 333, 664-666.

Palmieri, M. C., Lindermayr, C., Bauwe, H., Steinhauser, C., and Durner, J. (2010). Regulation of plant glycine decarboxylase by $S$-nitrosylation and glutathionylation. Plant Physiol. 152, 1514-1528.

Prado, A. M., Porterfield, D. M., and Feijo, J. A. (2004). Nitric oxide is involved in growth regulation and re-orientation of pollen tubes. Development 131, 2707-2714.

Romero-Puertas, M. C., Laxa, M., Matte, A., Zaninotto, F., Finkemeier, I., Jones, A. M., et al. (2007). $S$-nitrosylation of peroxiredoxin II E promotes peroxynitrite-mediated tyrosine nitration. Plant Cell 19, 4120-4130.

Sarti, P., Giuffre, A., Forte, E., Mastronicola, D., Barone, M. C., and Brunori, M. (2000). Nitric oxide and cytochrome $c$ oxidase: mechanisms of inhibition and NO degradation. Biochem. Biophys. Res. Commun. 274, 183-187.

Seth, D., Hausladen, A., Wang, Y. J., and Stamler, J. S. (2012). Endogenous protein $S$-Nitrosylation in $E$. coli: regulation by OxyR. Science 336, 470-473.

Shumaev, K. B., Kosmachevskaya, O. V., Timoshin, A. A., Vanin, A. F., and Topunov, A. F. (2008). Dinitrosyl iron complexes bind with hemoglobin as markers of oxidative stress. Methods Enzymol. 436, 445-461.

Simontacchi, M., Buet, A., Lamattina, L., and Puntarulo, S. (2012). Exposure to nitric oxide increases the nitrosyl-iron complexes content in sorghum embryonic axes. Plant Sci. 183, 159-166.

Singh, R. J., Hogg, N., Joseph, J., and Kalyanaraman, B. (1996). Mechanism of nitric oxide release from S-nitrosothiols. J. Biol. Chem. 271, 18596-18603.

Smith, J. N., and Dasgupta, T. P. (2000). Kinetics and mechanism of the decomposition of $S$ nitrosoglutathione by l-ascorbic acid and copper ions in aqueous solution to produce nitric oxide. Nitric Oxide $4,57-66$

Stamler, J. S., Toone, E. J., Lipton, S. A. and Sucher, N. J. (1997). (S)NO signals: translocation, regulation, and a consensus motif. Neuron 18, 691696.

Stubauer, G., Giuffre, A., and Sarti, P. (1999). Mechanism of S-nitrosothiol formation and degradation mediated by copper ions. J. Biol. Chem. 274, 28128-28133.

Tada, Y., Spoel, S. H., PajerowskaMukhtar, K., Mou, Z., Song, J., Wang, C., etal. (2008). Plant immunity requires conformational changes [corrected] of NPR1 via $S$ nitrosylation and thioredoxins. Science 321, 952-956.

Tello, D., Tarin, C., Ahicart, P., BretonRomero, R., Lamas, S., and MartinezRuiz, A. (2009). A "fluorescence switch" technique increases the sensitivity of proteomic detection and identification of $S$-nitrosylated proteins. Proteomics 9, 5359-5370.

Terrile, M. C., Paris, R., CalderonVillalobos, L. I., Iglesias, M. J., Lamattina, L., Estelle, M., et al. (2012). Nitric oxide influences auxin signaling through $S$-nitrosylation of the Arabidopsis TRANSPORT INHIBITOR RESPONSE 1 auxin receptor. Plant J. 70, 492-500.

Toledo, J. C. Jr., and Augusto, O. (2012). Connecting the chemical and biological properties of nitric oxide. Chem. Res. Toxicol. 25, 975-989.

Torta, F., and Bachi, A. (2012). Quantitative analysis of $S$-nitrosylated proteins. Methods Mol. Biol. 893, 405416.

Torta, F., Usuelli, V., Malgaroli, A., and Bachi, A. (2008). Proteomic analysis of protein $S$-nitrosylation. Proteomics 8, 4484-4494. van der Linde, K., Gutsche, N., Leffers, H. M., Lindermayr, C., Muller, B. Holtgrefe, S., et al. (2011). Regulation of plant cytosolic aldolase functions by redox-modifications. Plant Physiol. Biochem. 49, 946-957.

van der Vliet, A., Hoen, P. A., Wong, P. S., Bast, A., and Cross, C. E. (1998). Formation of $S$-nitrosothiols via direct nucleophilic nitrosation of thiols by peroxynitrite with elimination of hydrogen peroxide. J. Biol. Chem. 273, 30255-30262.

Vanin, A. F., Malenkova, I. V., and Serezhenkov, V. A. (1997). Iron catalyzes both decomposition and synthesis of $S$-nitrosothiols: optical and electron paramagnetic resonance studies. Nitric Oxide 1, 191-203.

Wang, X., Kettenhofen, N. J., Shiva, S., Hogg, N., and Gladwin, M. T. (2008). Copper dependence of the biotin switch assay: modified assay for measuring cellular and blood nitrosated proteins. Free Radic. Biol. Med. 44, 1362-1372.

Wang, Y. Q., Feechan, A., Yun, B. W., Shafiei, R., Hofmann, A., Taylor, P., et al. (2009). S-nitrosylation of AtSABP3 antagonizes the expression of plant immunity. J. Biol. Chem. 284 2131-2137.

Wiktorowicz, J. E., Stafford, S., Rea, H., Urvil, P., Soman, K., Kurosky, A., et al. (2011). Quantification of cysteinyl $S$-nitrosylation by fluorescence in unbiased proteomic studies. Biochemistry 50, 5601-5614.

Wilson, I. D., Neill, S. J., and Hancock, J. T. (2008). Nitric oxide synthesis and signalling in plants. Plant Cell Environ. 31, 622-631.

Wink, D. A., Nims, R. W., Darbyshire, J. F., Christodoulou, D., Hanbauer, I., Cox, G. W., et al. (1994). Reaction kinetics for nitrosation of cysteine and glutathione in aerobic nitric oxide solutions at neutral $\mathrm{pH}$. Insights into the fate and physiological effects of intermediates generated in the $\mathrm{NO} / \mathrm{O} 2$ reaction. Chem. Res. Toxicol. 7, 519-525.

$\mathrm{Xu}$, Y., Ding, J., Wu, L. Y., and Chou, K. C. (2013). iSNO-PseAAC: predict cysteine $S$-nitrosylation sites in proteins by incorporating position specific amino acid propensity into pseudo amino acid composition. PLoS ONE 8:e55844. doi: 10.1371/journal.pone.0055844

Xue, Y., Liu, Z., Gao, X., Jin, C., Wen, L., Yao, X., et al. (2010). GPS-SNO: computational prediction of protein $S$-nitrosylation sites with a modified
GPS algorithm. PLoS ONE 5:e11290. doi: 10.1371/journal.pone.0011290

Yu, M., Yun, B. W., Spoel, S. H., and Loake, G. J. (2012). A sleigh ride through the SNO: regulation of plant immune function by protein $S$ nitrosylation. Curr. Opin. Plant Biol. 15, 424-430.

Yun, B. W., Feechan, A., Yin, M., Saidi, N. B., Le Bihan, T., Yu, M., et al. (2011). S-nitrosylation of NADPH oxidase regulates cell death in plant immunity. Nature 478, 264-268.

Zhang, X., Huang, B., Zhang, L., Zhang, Y., Zhao, Y., Guo, X., et al. (2012). SNObase, a database for $S$ nitrosation modification. Protein Cell 3, 929-933.

Zhang, Y., Keszler, A., Broniowska, K. A., and Hogg, N. (2005). Characterization and application of the biotin-switch assay for the identification of $S$-nitrosated proteins. Free Radic. Biol. Med. 38, 874-881.

Zhao, D. Y., Tian, Q. Y., Li, L. H., and Zhang, W. H. (2007). Nitric oxide is involved in nitrate-induced inhibition of root elongation in Zea mays. Ann. Bot. 100, 497-503.

Zhou, X., Han, P., Li, J., Zhang, X., Huang, B., Ruan, H. Q., et al. (2010). ESNOQ, proteomic quantification of endogenous S-nitrosation. PLoS ONE 5:e10015. doi: 10.1371/journal.pone.0010015

Conflict of Interest Statement: The authors declare that the research was conducted in the absence of any commercial or financial relationships that could be construed as a potential conflict of interest.

Received: 14 February 2013; paper pending published: 06 March 2013; accepted: 22 April 2013; published online: 14 May 2013.

Citation: Kovacs I and Lindermayr $C$ (2013) Nitric oxide-based protein modification: formation and site-specificity of protein S-nitrosylation. Front. Plant Sci. 4:137. doi: 10.3389/fpls.2013.00137

This article was submitted to Frontiers in Plant Proteomics, a specialty of Frontiers in Plant Science.

Copyright (c) 2013 Kovacs and Lindermayr. This is an open-access article distributed under the terms of the Creative Commons Attribution License, which permits use, distribution and reproduction in other forums, provided the original authors and source are credited and subject to any copyright notices concerning any third-party graphics etc. 